\title{
COMMENT
}

\section{Development of web-based guides to planktonic protists}

\author{
Michaela C. Strüder-Kypke*, David J. S. Montagnes** \\ Port Erin Marine Laboratory, University of Liverpool, Port Erin, Isle of Man IM9 6JA, British Isles
}

\begin{abstract}
Computer-based media constitute an ideal tool for disseminating data concerning protist biodiversity. Interactive guides can combine micrographs, illustrations, text and links to molecular data. A standardized web-based guide could collate information collected by researchers and create a mechanism for ecologists to identify taxa. Web-based guides have advantages: they are easily modified and expanded; they are easy to distribute; they can include a search engine to replace a dichotomous key; they can be downloaded to run on stand-alone computers; and they can be structured to provide printed information. We have developed a model for a guide that incorporates these methods of disseminating information. Using this model, we indicate how the web can provide information and act as a tool to identify taxa. We then use a guide to the planktonic ciliates, based on this model, as an example (www.liv.ac.uk/ciliate). Finally we present data from a survey that reviewed our model website; it indicated that the site was well received. Ultimately, we offer this guide as a template to be applied to other taxa.
\end{abstract}

KEY WORDS: Biodiversity $\cdot$ Ciliate $\cdot$ Internet $\cdot$ Key $\cdot$ Plankton · Taxonomy

Resale or republication not permitted without written consent of the publisher

Computer-based media constitute a powerful and flexible tool for scientific communication and collaboration. They are ideal for disseminating information regarding protist biodiversity to ecologists, as guides can combine micrographs, illustrations, text and links to molecular data. Guides to protists exist on CD ROM (e.g. Estep et al. 1992), but like books, once produced they can be costly and difficult to modify. Several websites also provide illustrated guides to protists (e.g. www.marbot.gu.se; http://protist.i.hosei.ac.jp/Protist_menuE.html; www.mbl.edu/microscope), but these generally lack a mechanism to identify taxa. Developing a standardized guide would provide an opportu-

\footnotetext{
*Present address: Department of Zoology, University of Guelph, Guelph, N1G 2W1 Ontario, Canada

${ }^{* *}$ Corresponding author. E-mail: dmontag@liv.ac.uk
}

nity to combine existing information and create a tool for ecologists to identify taxa. Clearly, as the protists are a diverse group, they are unlikely to all be covered by 1 database. However, following a model, with minor taxon-specific variations, a network could be developed to cover a broad range of taxa.

Web-based guides have advantages: (1) they can easily be modified, expanded and distributed; (2) they can incorporate a search engine to replace a dichotomous key; (3) they can be downloaded to run on standalone computers; and (4) they can provide printed information when computers are unavailable. In this comment we indicate how the web can provide information and act as a tool to identify taxa. Specifically, we use a guide based on the above criteria as an example. We offer this guide as a template that could be extended to other groups, thus reducing the potential chaos that may arise due to multiple development of such websites.

General model. Oceanographers and limnologists recognize the importance of protists in pelagic food webs, but ecologists are rarely specialized taxonomists. Thus, their studies tend to group protists according to size classes and nutritional modes: e.g. nanoplankton, microplankton, autotrophs, mixotrophs, heterotrophs (Sieburth et al. 1978, Azam et al. 1983). Protists, however, exhibit species-specific traits and cannot be considered as functional groups any more than can all phytoplankton or all mesozooplankton (e.g. Montagnes 1996). As the existing groups do not reflect the functional biodiversity of protists, ecologists require methods to identify taxa.

Although automated methods are being developed to examine samples (e.g. Sieracki et al. 1998), inverted light microscopy remains a standard method to identify and enumerate planktonic protists. Thus, guides need to be based primarily on micrographs and illustrations but can then be complemented by written descriptions and ecological data (e.g. habitat, food preference, salinity). Such guides need to be expandable and easy 
to use. Furthermore, to be applicable to ecological studies, they must focus on the preserved specimens collected in routine field samples, but to be versatile they must also include data used in taxonomic descriptions. We propose a guide format that fulfills the criteria and can potentially be applied to all protist groups (Fig. 1).

In our generalized guide (Fig. 1), the main component is a series of 'data sheets', each presenting 1 species. The data sheets act as file-cards and contain all the text and illustrations needed to identify a single taxon. Data sheets can be viewed in any order on the computer or can be printed and viewed as hardcopies. Augmenting the data sheets are several modules, linked to each data sheet: a 'taxonomic overview'; an 'illustrated glossary'; a 'methods section'; and a 'references section'. To minimize memory needs and access times, the data sheets appear on-screen at a relatively low resolution, but both the text and illustrations can be enlarged simply by clicking on the page. This provides a visually pleasing, book-like appearance while maintaining the versatility of the internet.

Taxa can be accessed by 3 methods: from a list of all species; through general groupings (higher taxa); and via a search engine. By partitioning the guide, as described above, new species (data sheets) can be added; likewise, the other components can be updated in isolation and new modules can be added. Finally, an entire

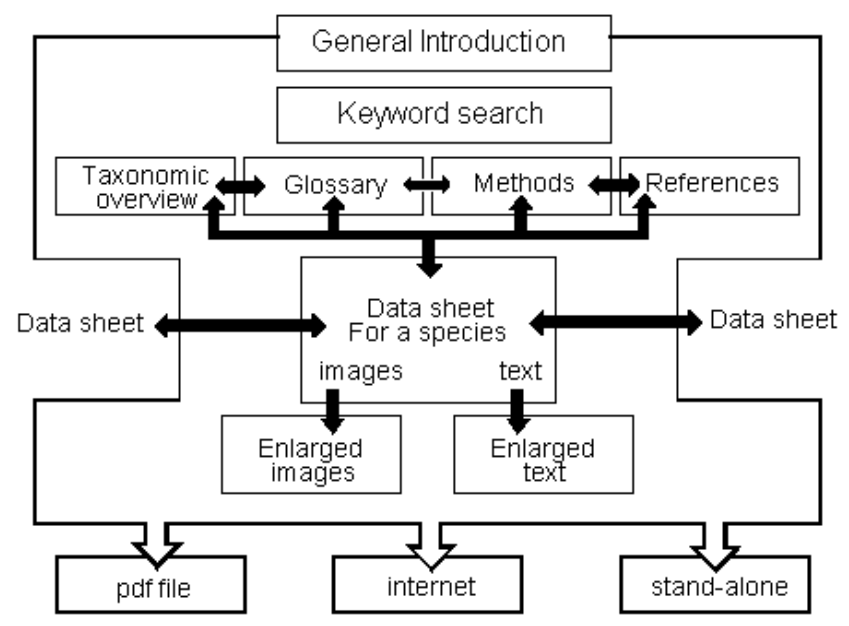

Fig. 1. Model of a generalized web-based guide to protists. The central component of the model is a series of data sheets that describe each species (e.g. Fig. 2c). Each data sheet presents a low-resolution, holistic view of the species. Individual illustrations and text components of each data sheet can be enlarged for viewing (e.g. Fig. 2d). Supporting and linked to (arrows) the data sheets are several modules (e.g. an illustrated glossary; Fig. 2b). There is also a general introduction and a keyword search element to the website. A portion of or the entire website can be accessed via the internet, downloaded to a hard drive or a CD ROM drive of a personal computer, or printed as a hardcopy (pdf format) new set of data sheets, presenting a different group, could be linked to the site. Thus, the guide can be expanded to other groups, using a modular approach.

Our generalized guide is also versatile in its accessibility: (1) it can be viewed online; (2) it can be downloaded to a hard drive and browsed offline, improving the performance if internet access is slow; and (3) all pages can be printed, following international standards (i.e. compatible with letter and A4 formats), providing information when computers are not available.

Using the above criteria as a model, we are developing a guide to identify marine planktonic ciliates, collected during routine sampling. Our audience is primarily ecologists, students and amateur naturalists who are not ciliate taxonomists, but we also hope to provide data for experts in the field. To date we have assembled a database of ciliates from coastal waters by reviewing the literature and supplementing these data with information from new samples. Below we briefly describe the site and discuss how it reflects our model.

The user-friendly guide to marine planktonic ciliates: a test case. The ciliates are a diverse and important group in many planktonic food webs (Reid et al. 1991, Pierce \& Turner 1992). However, they can be difficult to identify; thus, the role of individual taxa is often neglected.

To date, there is no comprehensive guide to the marine planktonic ciliates. Their taxonomy has radically changed over the last $20 \mathrm{yr}$, primarily due to improved light- and electron-microscope studies and new molecular methods (Small \& Lynn 1985, Lynn \& Small 1997). Furthermore, many species descriptions date from the late 19th and early 20th centuries and are based on live or poorly fixed samples. Therefore, the older literature lacks the rigor currently applied to ciliate taxonomy (Montagnes \& Lynn 1991, Foissner 1994). Finally, modern descriptions are generally presented in isolated publications, leading to extensive searches when taxa require identification.

Some general guides exist that provide an overview of the diversity and characteristics of higher taxa (e.g. Lee et al. 1985, Patterson 1992), but only a small percentage of the marine planktonic species are illustrated in these guides. In contrast, Foissner and his colleagues have developed several user-friendly guides to freshwater ciliates (e.g. Foissner \& Berger 1996, Foissner et al. 1999); the success of these guides indicates the needs and interests of the scientific community. We have built on this user-friendly approach and have extended our concept to electronic media.

Our guide focuses on Lugol's iodine fixed samples, since Lugol's is widely used as a standard fixative for ciliates and other plankton, is relatively inexpensive, is relatively non-toxic, and maintains the taxonomic integrity of samples (Gifford \& Caron 2000). However, 
Lugol's renders cells dark brown and may distort cells, making them difficult to recognize. Thus, to fully describe taxa, more rigorous identification methods must be employed. For instance, the specialized technique of protargol staining reveals diagnostic features of ciliates and is a standard for taxonomic work. Protargol staining is, however, elaborate and time consuming and is rarely used in ecological studies (Montagnes \& Lynn 1993). Thus, we provide criteria for identifying ciliates that have been fixed with Lugol's; then, when possible we augment these with data from protargolstained, live and scanning electron microscopy (SEM) samples. We have also taken a further step with Lugol's fixed material. We use nuclear shape and position, normally not seen in Lugol's stained cells, as a diagnostic feature. We do this by post-staining Lugol's fixed material with the nuclear fluorochrome $4{ }^{\prime}, 6$ - diamidino-2-phenylindole (DAPI) (Montagnes et al. unpubl.). Finally, we include data from ecological studies. The combination of these data improves the identification of ciliates and helps to indicate their importance in food webs.

As outlined above, the information in the guide is structured as several modules. General chapters complement the information given on the 'data sheets' (Fig. 1). The 'methods section' explains the common sampling, fixation and staining techniques. The 'schematics section' provides generalized drawings of the ciliate groups (Fig. 2a); each species is assigned to 1 group, and links are provided to its data sheet. Features illustrated in the schematic diagrams are labeled and linked to the illustrated 'glossary' (Fig. 2b). Finally, the 'references section' contains the bibliography for the entire website.
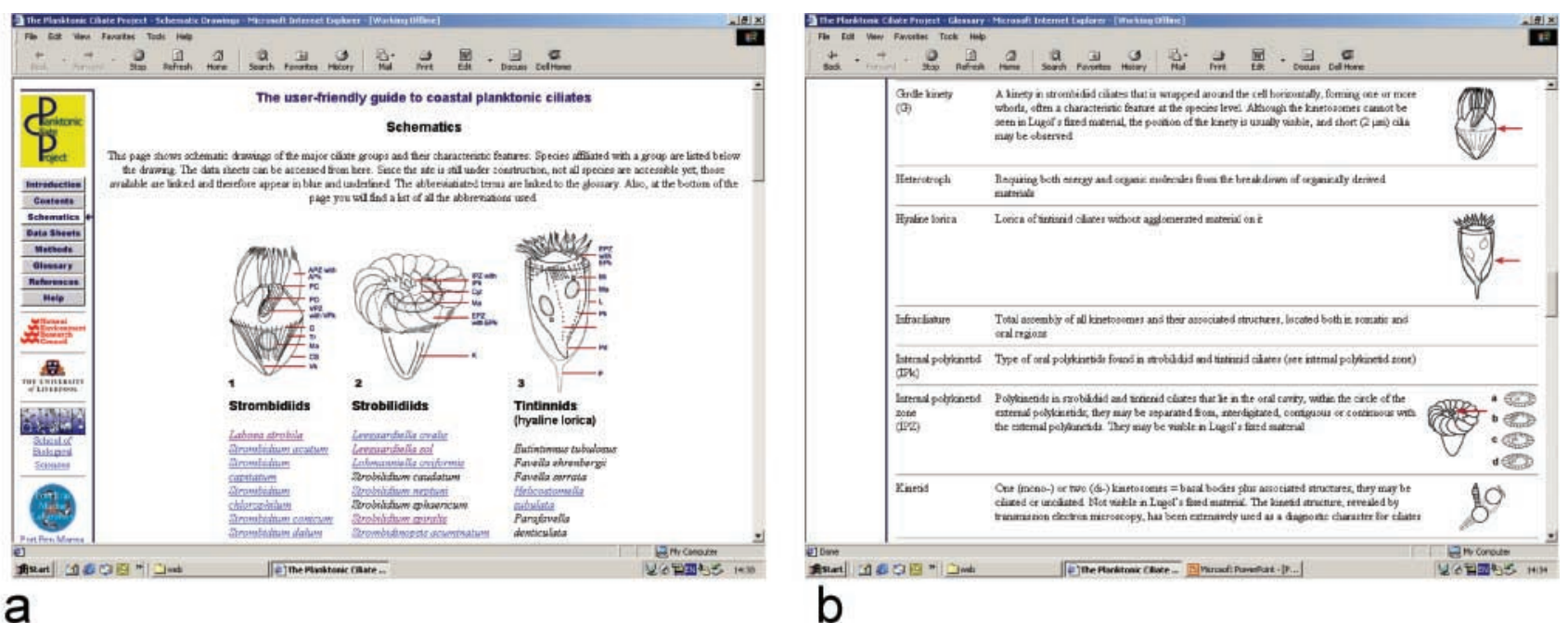

a

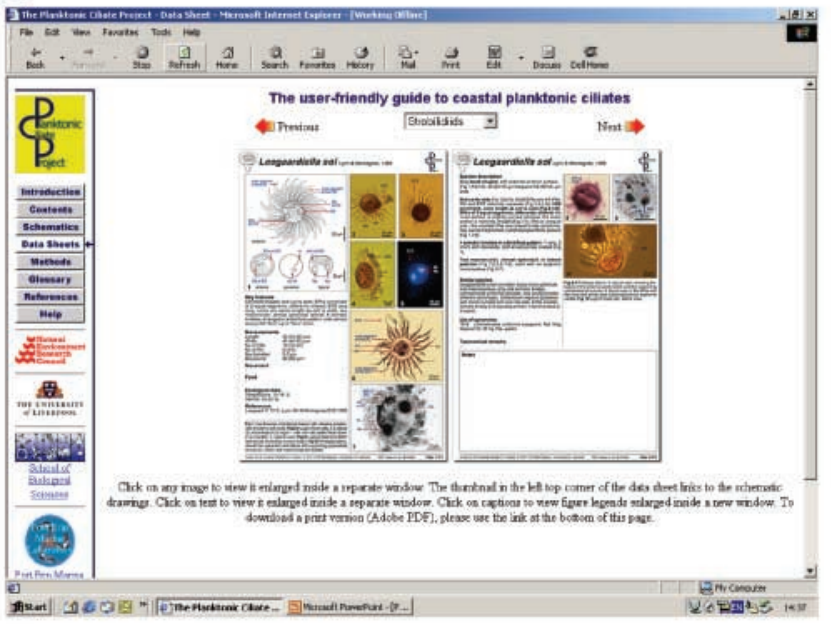

C

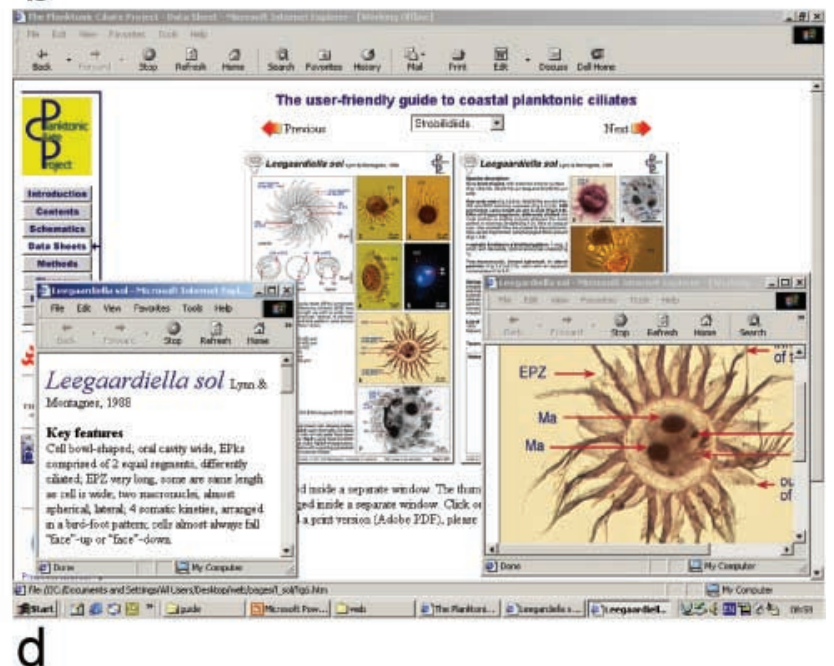

Fig. 2. Examples of 4 components of the guide to planktonic ciliates, following the model described in the text and Fig. 1. (a) A portion of the schematic page, containing diagrams of major taxonomic groups and a list of taxa associated with each group. (b) A portion of the illustrated glossary. (c) A data sheet, indicating the book-like, holistic view of a species description. (d) Data sheet with enlarged components of illustrations and text 
Data sheets can be accessed from the 'contents section', which lists the species alphabetically; from the schematics section (Fig. 2a); or via a keyword search on the website. Initially, the entire data sheet is shown (Fig. 2c). The data sheets appear as 2 pages of a book and provide a holistic impression of the species: drawings; photos of Lugol's, DAPI- and protargol-stained cells; and SEM images. Each picture can then be enlarged and viewed separately (Fig. 2d).

The text of the data sheets is divided as follows: key features; measurements and biovolume; movement; ecological data; references to original papers; a taxonomic description; a list of similar species (linked to the corresponding data sheets); and a taxonomic section (list of synonyms and remarks). The search engine enables the user to locate specific text. Thus, the user is offered an interactive tool to identify a species by using key characters and reading species descriptions (Fig. 2d).

Finally, the information can be downloaded as a pdf file and printed in a standard format (letter or A4). This approach reflects the traditional method of publishing. However, the choice of which pages to print makes the product inexpensive and open to editorial changes and additions.

The guide can be fully cited as follows: Strüder-Kypke MC, Kypke ER, Agatha S, Warwick J, Montagnes DJS (2000-2001) The user-friendly guide to coastal planktonic ciliates. www.liv.ac.uk/ciliate.

Assessment and evaluation. One disadvantage of the internet is the lack of quality control; published data are often not peer reviewed. Meanwhile, the internet offers a new approach to the reviewing process in terms of open discussion groups. Users can post comments and questions to the webmaster, and chatrooms, assigned to the website, can be open to everyone. As the contents of the website are improved this feedback provides collaboration between users and authors.

To assess the effectiveness of our website and to evaluate whether we are achieving our aims, we distributed an electronic questionnaire. From a wide range of colleagues ( 140), 15\% answered the questionnaire and another $5 \%$ provided comments. Generally, the feedback was positive, supporting the need of such a guide; $87 \%$ plan to use the guide regularly (weekly to monthly) for part of their research. Thus, there does appear to be a need for such websites.

The structure and instructions of the website were appreciated (90 and $76 \%$, respectively), indicating our general model was well accepted. Rather than criticizing the existing template, most comments recommended additions. Changes were required in terms of adding information; e.g. the references (38\%) and methods (33\%) modules need expansion. Furthermore, increasing the diversity of ciliate species $(28 \%)$ or other protist taxa $(37 \%)$ was supported. Several researchers suggested adding an identification key to the website; this is planned for the future, when sufficient ciliate species are included.

Our aim at providing a visual guide was also appreciated, as the images in the data sheets were accepted as useful: the schematic drawings and the protargol images were considered to be very useful (85 and $76 \%$, respectively), and images of the other 3 methods, Lugol's (45\%), DAPI (52\%) and SEM (53\%), were well received but considered to be less important. However, the combination of all information given by the images was regarded as extremely helpful in species determination (85\%). Furthermore, the micrograph quality was considered adequate or better $(71 \%)$, and the technical quality was generally acceptable (63\%).

Most researchers accepted the downloading times for the components (data sheets, images, pdf files, entire site) as relatively short. Thus, our last aim was realized: we have designed an easily accessible method to disseminate information using 3 methods: the internet, stand-alone computers and hard copies.

Conclusion. The positive reaction of the scientific community indicates the need for an accessible and modifiable web-based guide to the protists. Furthermore, the structure we have provided was supported. We realize that the extensive diversity of the protists cannot easily be covered by 1 website, but the concept and development of our guide to planktonic ciliates provide an opportunity for collaboration and expansion to other taxa. Several modular websites following the same format, dealing with different organisms, could be linked to a general database and guide to the protists. Thus, the collective knowledge of many researchers could be incorporated into 1 project. We are still developing our site and invite your comments, suggestions and contributions (ciliates@liv.ac.uk). Ultimately, we envisage developing a global site, following the model described above, and we invite collaboration to this end.

Acknowledgements. This work was funded by the NERC Marine Productivity Programme (GST/02/2748) and by Manx Airlines. We are grateful to our collaborators on the website: E. Reinhard Kypke, Sabine Agatha and John Warwick. We also thank others who have provided assistance: Kimberley Earland; D. Roberts and A. Warren (Natural History Museum, London); and Akira Kihara (Hosei University, Tokyo).

\section{LITERATURE CITED}

Azam F, Fenchel T, Field JG, Gray JS, Meyer-Reil LA, Thingstad $F$ (1983) The ecological role of water-column microbes in the sea. Mar Ecol Prog Ser 10:257-263

Estep KW, Rey F, Bjørklund K, Dale T and 7 others (1992) 
Deus creavit; Linneaus disposuit : an international effort to create a catalogue and expert system for the identification of protistan species. Sarsia 77:275-285

Foissner W (1994) Progress in taxonomy of planktonic freshwater ciliates. Mar Microb Food Webs 8:9-35

Foissner W, Berger H (1996) A user-friendly guide to the ciliates (Protozoa, ciliophora) commonly used by hydrobiologists as bioindicators in rivers, lakes, and waste waters, with notes on their ecology. Freshw Biol 35: $375-842$

Foissner W, Berger H, Schaumburg J (1999) Identification and ecology of limnetic plankton ciliates. Informationsber Bayer Landesamt Wasserwirtsch 3/99:793

Gifford DJ, Caron DA (2000) Sampling, preservation, enumeration and biomass of marine protozooplankton. In: Harris RP et al. (eds) ICES zooplankton methodology manual. Academic Press, London, p 193-221

Lee JJ, Hutner SA, Bovee EC (1985) An illustrated guide to the protozoa. Society of Protozoologists, Lawrence, p 629

Lynn DH, Small EB (1997) A revised classification of the phylum Ciliophora Doflein, 1901. Rev Soc Mex Hist Nat 47: 65-78

Montagnes DJS (1996) Growth responses of planktonic ciliates in the genera Strobilidium and Strombidium. Mar Ecol Prog Ser 130:241-254

Editorial responsibility: John Dolan, Villefranche-sur-Mer, France
Montagnes DJS, Lynn DH (1991) Taxonomy of the major groups of marine planktonic ciliates, with emphasis on the aloricate forms. Mar Microb Food Webs 5:59-74

Montagnes DJS, Lynn DH (1993) A quantitative protargol stain (QPS) for ciliates and other protists. In: Kemp PF, Sherr BF, Sherr EB, Cole JJ (eds) Handbook of methods in aquatic microbial ecology. Lewis Publishers, Boca Raton, p 229-240

Patterson DJ (1992) Free-living freshwater protozoa: a colour guide. Manson Publishing, London

Pierce RW, Turner JT (1992) Ecology of planktonic ciliates in marine food webs. Rev Aquat Sci 6:139-181

Reid PC, Turley CM, Burkill PH (1991) Protozoa and their role in marine processes. NATO ASI publication. Springer, New York

Sieburth JM, Smetacek V, Lenz J (1978) Pelagic ecosystem structure: heterotrophic compartments of the plankton and their relationship to plankton size fractions. Limnol Oceanogr 23:1256-1263

Sieracki CK, Sieracki ME, Yentsch CS (1998) An imaging-inflow system for automated analysis of marine microplankton. Mar Ecol Prog Ser 168:285-296

Small EB, Lynn DH (1985) Phylum Ciliophora. In: Lee JJ, Hutner SA, Bovee EC (eds) An illustrated guide to the protozoa. Society of Protozoologists, Lawrence, p 393-575

Submitted: December 4, 2001; Accepted: December 21, 2001 Proofs received from author(s): February 28, 2002 